\title{
Failure behavior of coated nickel-based superalloy under thermomechanical fatigue
}

\author{
Z. B. Chen $\cdot$ Z. W. Huang $\cdot$ Z. G. Wang $\cdot$ \\ S. J. Zhu
}

Received: 24 May 2009/Accepted: 27 August 2009/Published online: 10 September 2009

(c) The Author(s) 2009. This article is published with open access at Springerlink.com

\begin{abstract}
Thermomechanical fatigue (TMF) is a major life limiting factor for gas turbine blades. In this study, the failure behavior of NiCrAlY overlay coated nickel-based superalloy M963 was investigated under out of phase (OP) TMF. All tests were carried out under mechanical strain control with a cyclic period of $200 \mathrm{~s}$. Results revealed that the fatigue life of high velocity oxygen fuel spraying (HVOF) coated specimen was longer than that of air plasma spraying (APS) coated one, but shorter than that of bare superalloy M963 at a given strain range. It was found that cracking process in the APS coating was different from that in the HVOF coating, which was shown by the sketches to understand the crack initiation and propagation behavior.
\end{abstract}

\section{Introduction}

Nickel-based superalloys are widely used as hot section components in gas turbines for aircraft and power generation. The maximum operational temperature for nickelbased single crystal superalloys used for blades has reached $\sim 1100{ }^{\circ} \mathrm{C}$ with development of processing technology and alloy design methodology [1]. However, in today's engines, the hot gas temperatures still exceed the melting point of the nickel-based superalloy by more than $250{ }^{\circ} \mathrm{C}$

Z. B. Chen · Z. W. Huang · Z. G. Wang

Shenyang National Laboratory for Materials Science, Institute of Metal Research, Chinese Academy of Sciences, 72 Wenhua Road, Shenyang 110016, People's Republic of China

\section{S. J. Zhu $(\bowtie)$}

Department of Intelligent Mechanical Engineering, Fukuoka Institute of Technology, Higashi-ku, Fukuoka 811-0295, Japan e-mail: zhu@fit.ac.jp
[2]. Oxidation and hot corrosion severely degrade their performance. In order to achieve higher capability and longer life, protective coatings are often applied to superalloys. One class of coatings is diffusion coating, which is Pt-modified or newly developed $\mathrm{Zr}$-doped aluminides [3, 4]; the other class of coatings is the so-called MCrAlY overlay coating (where $\mathrm{M}$ is $\mathrm{Ni}, \mathrm{Co}, \mathrm{Fe}$, or a combination of these elements), which is sprayed in a wide variety of compositions to the relevant substrate materials [5].

Hot section components undergo severe cyclic thermal and mechanical loads during service and thus thermomechanical fatigue (TMF) provides a closer simulation of the actual strain-temperature cycle that coating and substrate experience in an engine environment [6, 7]. However, since TMF tests are difficult to be performed only a few studies are available in the open literature [8-13]. Among the previous experiments, Kowalewski and Mughrabi [10] found that the out of phase (OP) TMF life of low pressure plasma spraying (LPPS) NiCrAlY coated directionally solidified nickel-based superalloy was shorter than that of the bare substrate. Nützel et al. [11] investigated the counter clockwise diamond (CCD)-TMF of monocrystalline nickel-based superalloy coated with Pt-modified $\beta$-NiAl and showed that the life of coated specimens was also shorter than that of the bare substrate. Zamrik and Renauld [13] studied OP TMF behavior of LPPS NiCoCrAlY coated cast superalloy IN-738LC, and reported that the coating affected the fatigue life by delaying crack growth into the substrate, and the coating enhanced the OP TMF life at high strain ranges but reduced the life at low strain ranges. Zhang et al. [12] performed $135^{\circ}$ lag OP TMF of the aluminide coated single crystal Ni-based superalloy and revealed that at a high strain range the TMF life of coated substrate was shorter than that of the bare substrate, while at a low strain range the TMF life of coated substrate was 
longer. Kadioglu and Sehitoglu [9] compared the TMF behavior of bare and the nickel-aluminum (NiAl) coated superalloy and found the life was almost the same between the coated and bare substrate at low strain rate, and the main cracks originated from surface of the coating in both cases of isothermal fatigue and OP TMF. Of the limited studies, the influences of coatings on TMF lives were either detrimental, or beneficial or negligible, depending on fatigue testing conditions and material systems. The TMF damage and fracture mechanisms are not understood. As a result, it is difficult to give guidelines for developing a reliable coating system and predicting TMF life of components. A lot of problems and questions on TMF behavior need to be solved by TMF experiments and analysis.

The high velocity oxygen fuel spraying (HVOF) is a new technique for forming MCrAlY coating with good microstructure, high adhesive strength, and low operating costs [14]. A number of studies were carried out on oxidation [15, 16], indentation, and hardness [17] of HVOF NiCrAlY coated superalloy, but there was no report on TMF of HVOF coated superalloy. The aims of this paper are to investigate the effects of HVOF NiCrAlY overlay coating on the TMF life, compared to the TMF life of plasma sprayed coating, and to understand the dominant failure mechanisms which are important for development of reliable coatings.

\section{Experimental}

The substrate material used in this paper was M963, a cast nickel-based superalloy used for vanes and blades in gas turbine engine. Its chemical composition (in wt\%) was $\mathrm{C}$ 0.15, Cr 8.89, Al 6.00, Ti 2.55, Mo 1.64, W 10.1, Co 10.0, $\mathrm{Nb} 1.10, \mathrm{Zr} 0.03$, B 0.03, Ce 0.02, Y 0.01, and Ni balance. Before machining, the specimens were solution-treated at $1210{ }^{\circ} \mathrm{C}$ for $4 \mathrm{~h}$ and followed by air cooling. Cylindrical specimens had a gauge diameter of $6 \mathrm{~mm}$ and a gauge length of $25 \mathrm{~mm}$ as shown in Fig. 1. The gauge length of the specimen was coated either by air plasma spraying (APS) or by HVOF with a Ni-25Cr-5Al-0.5Y alloy powder (200-300 mesh) as displayed by oblique lines in



Fig. 1 Geometry of thermomechanical fatigue test specimens (dimension in $\mathrm{mm}$ )
Fig. 1. The nominal thickness of the coating is $130 \mu \mathrm{m}$. The APS coating was produced by METCO $7 \mathrm{M}$ under the following conditions: argon gas atmosphere at 0.4 $0.6 \mathrm{MPa}$, voltage at $40-60 \mathrm{~V}$, current at 500-530 A, spraying distance $145-150 \mathrm{~mm}$. The HVOF equipment is JP-5000HP/HVOF of Hobart Tafa, and the spray parameters have described elsewhere [18].

The TMF tests were performed on a MTS810 closedloop servohydraulic testing machine with computer control. A high-frequency induction generator was used for heating. Cooling was mainly achieved by thermal conduction into the water cooling specimen grips and forced by blowing compressed air. Axial strain measurements were obtained using a self-supporting extensometer which has a gauge length of $16 \mathrm{~mm}$ and was supported with ceramic rods. Temperature control was conducted with a thermocouple spot-welded in the middle of the gauge length. A triangle waveform was used for both thermal cycling and mechanical cycling. OP TMF, in which the tensile strain is at a maximum when the temperature is at a minimum [6], are found to be the most damaging factor on the loading edge of a gas turbine blade from repeated turbine starts and stops and cause the highest damage [13]. OP TMF tests were carried out in the temperature range of $450-900{ }^{\circ} \mathrm{C}$ with a cyclic period of $200 \mathrm{~s}$ under mechanical strain control. In this study, a mechanical strain amplitude of $0.35 \%$ was applied, with a strain ratio $R=-1$, as shown in Fig. 2. A series of interrupted tests at $\Delta \varepsilon_{\text {mech }} / 2=0.35 \%$ were carried out to analyze the crack propagation and calculate the crack density. After the TMF tests, metallographically prepared section of longitudinal section (cutting from fracture surface or in the middle of the specimen parallel to the loading direction) as well as the fracture surfaces were observed using a scanning electron microscope (SEM).

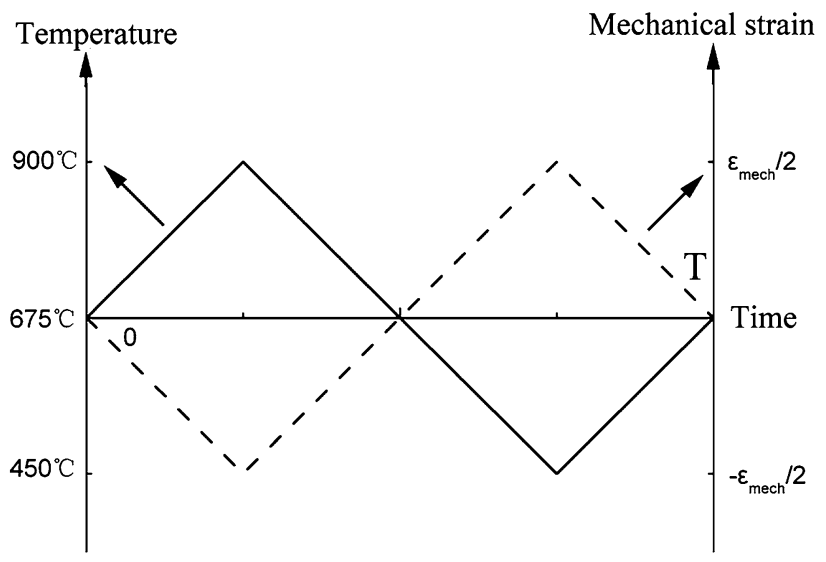

Fig. 2 Cycle shape in terms of temperature and mechanical strain versus time under $\mathrm{OP}$ TMF 
Fig. 3 The microstructure of as sprayed condition coating processed by a APS and b HVOF
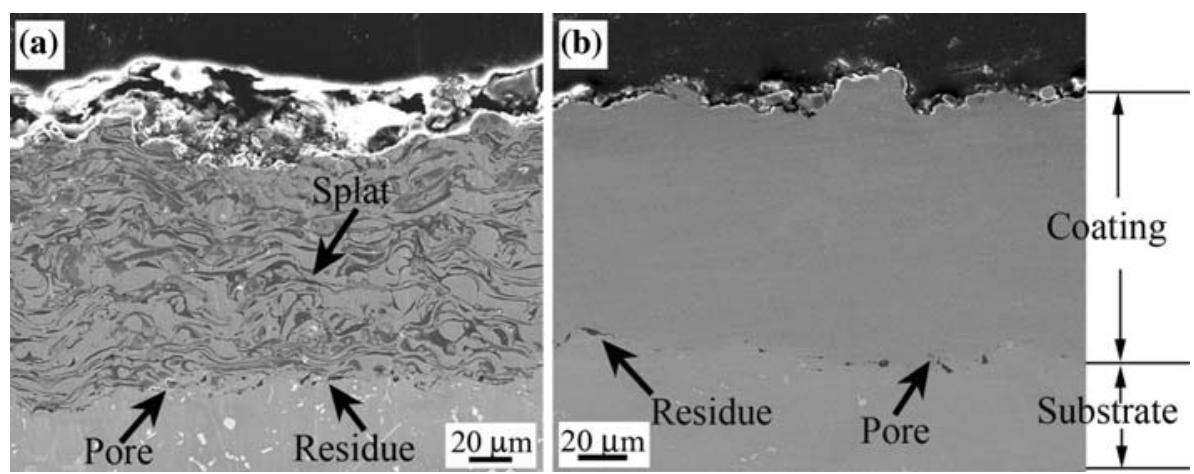

\section{Results and discussion}

The microstructures of the coating in as sprayed condition are shown in Fig. 3. It can be seen that many splats appear in the APS coating, the surface of coating and the interface are uneven, and pores or residue are found in the interface, as shown in Fig. 3a. However, the HVOF coating looks just like an entire smooth block although pores or residue are also found in the interface (see Fig. 3b). It is believed that

Table 1 OP TMF life of three material systems at $\Delta \varepsilon_{\text {mech }} / 2=0.35 \%$

\begin{tabular}{llll}
\hline Specimen & $\begin{array}{l}\text { APS coated } \\
\text { specimen }\end{array}$ & $\begin{array}{l}\text { HVOF coated } \\
\text { specimen }\end{array}$ & $\begin{array}{l}\text { Bare } \\
\text { specimen }\end{array}$ \\
\hline $\begin{array}{l}\text { Number of cycles } \\
\text { to failure }\end{array}$ & 298 & 402 & 576 \\
\hline
\end{tabular}

the different microstructures between APS and HVOF coating will lead to different fatigue lives and fracture mechanisms.

The OP TMF lives of three material systems at $\Delta \varepsilon_{\text {mech }} /$ $2=0.35 \%$ are summarized in Table 1 . From the number of cycles to failure, it appears that the life of HVOF coated specimen is longer than that of APS coated specimen. It can also be seen that the coating reduced the TMF life compared to the uncoated specimens. To explain this phenomenon, it is necessary to observe the characteristics of fracture surfaces and crack initiation and propagation behavior.

The fracture surface of a failed APS coated specimen at $\Delta \varepsilon_{\text {mech }} / 2=0.35 \%$ is shown in Fig. 4 a. It can be seen that the outside circumferential area of the substrate is circled by black area indicated by arrows, which is validated as
Fig. 4 a Fracture surface of APS coated specimen at $\Delta \varepsilon_{\text {mech }} /$ $2=0.35 \%$, the arrows showing the black area. b Crack path at the longitudinal section of APS coated specimen at $\Delta \varepsilon_{\text {mech }} /$ $2=0.35 \%$ and $\mathbf{c}-\mathbf{e}$ Illustration of cracking process in APS coated specimens under OP TMF


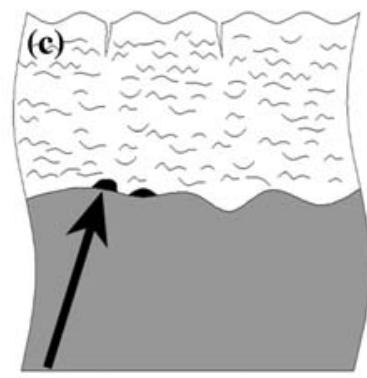

Pore
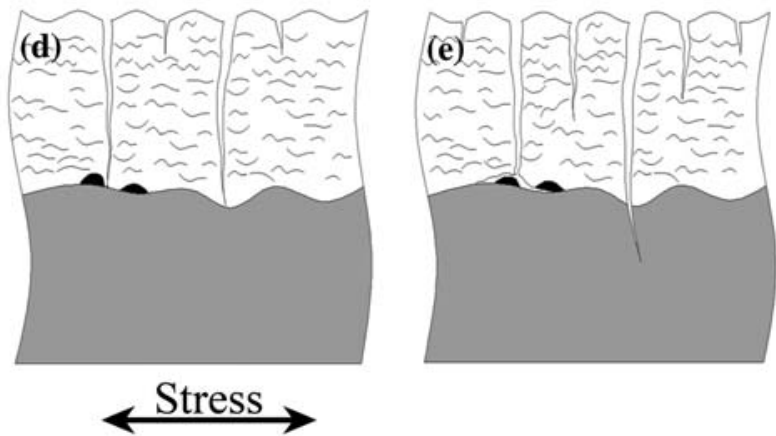
oxides of $\mathrm{Ni}, \mathrm{Cr}$ etc. This means that the multiple fatigue cracks initiate from the coating simultaneously; and after cracks pass through the coating, it takes a long time to initiate cracks in the substrate. Similar phenomenon was also found in $135^{\circ}$ lag OP TMF of coated single crystal Ni-based superalloy at $\Delta \varepsilon=1.0 \%$ [12]. The longitudinal section close to fracture surface is shown in Fig. 4b. It can be seen that the crack initiates from the trough of the surface, and then propagates to the interface. Subsequently, the crack passes through the interface or penetrates into the substrate. This is consistent with the morphology of the fracture surface (Fig. 4a). A schematic diagram of failure processes of the APS coated specimen based on the detailed observation is shown in Fig. 4c-e. The coating is brittle below the ductile-to-brittle transition temperature (DBTT), which is approximately $650{ }^{\circ} \mathrm{C}$ [5]. The defects or troughs at the coating surface are locations of stress concentration under tensile condition when the test is at low temperature cycle. The brittle coating easily breaks up at all above places at first (Fig. 4c). The crack number increases and the crack length becomes large with an increase in number of cycles. Then cracks pass through the coating and arrive at the interface (Fig. 4d). When cracks are at the interface, the propagation paths get complex which depend on the bonding strength between the coating and the substrate, which is influenced by the thermal residual stress [19], and other factors. When the interface is uneven, the bonding strength is strong because of the anchor effect [20], therefore the substrate experiences great stress concentration and severe localized environmental attack at high temperature at these uneven places (e.g. troughs), cracks develop from these sites into the substrate; the crack propagates along the interface when it is flat and locally defective which impairs the bonding force, therefore the bonding strength is weak (Fig. 4e). This causes more substrate surface to expose to the high temperature and leads to more severe oxidation; it corresponds to the cracking behavior in Fig. 4b.

The fracture surface of a failed HVOF coated specimen at $\Delta \varepsilon_{\text {mech }} / 2=0.35 \%$ is shown in Fig. $5 \mathrm{a}$. It can be seen that cracks initiate from the coating as shown by arrows and scalloping area is also found. This also indicates that the crack originates from the coating. The longitudinal section close to fracture surface is shown in Fig. 5b. It can be seen that the crack propagation in a similar way as that in APS coating. The crack originates from the trough of the coating, and then passes through the coating, at last penetrates into the substrate. A schematic diagram of failure processes of HVOF coated specimen is shown in Fig. 5c-e. Like the APS coating, the HVOF coating is also brittle at the low temperature cycle. The propagation behavior of cracks, which originates from coating, is the same as that of the APS coating. The crack not only develops from the surface, but can also initiate from the interface as shown in
Fig. 5 a Fracture surface of HVOF coated specimen at $\Delta \varepsilon_{\text {mech }} / 2=0.35 \%$, the arrows showing the crack initiation sites. b Crack path at the longitudinal section of $\mathrm{HVOF}$ coated specimen at $\Delta \varepsilon_{\text {mech }} /$ $2=0.35 \%$ and $\mathbf{c}-\mathbf{e}$ Illustration of cracking processes in $\mathrm{HVOF}$ coated specimens under OP TMF
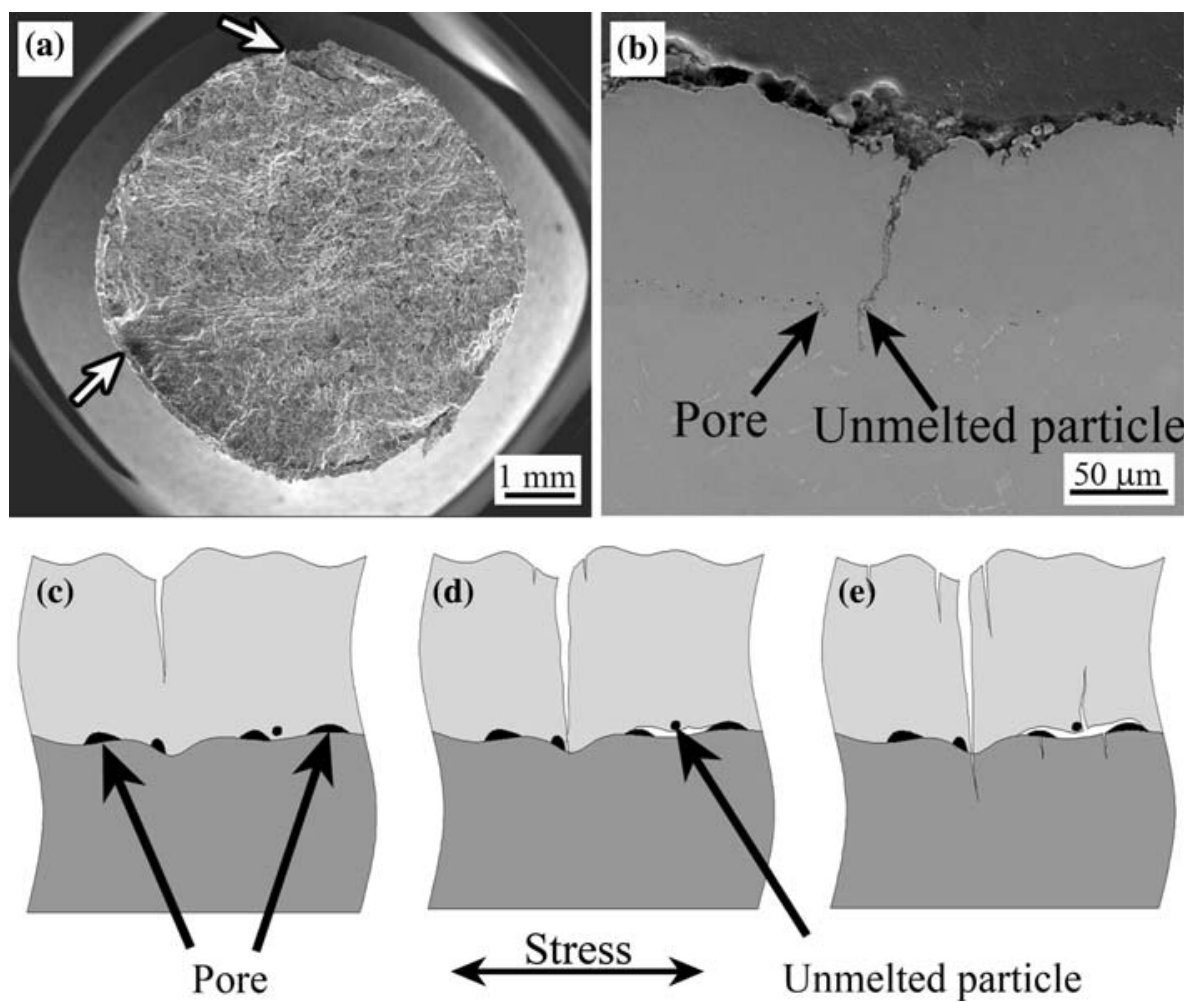
Fig. 5d. The unmelted particles or pores where the stress is concentrated are the preferred crack initiation sites. Then the crack extends along the interface, and at last deflects into the substrate and the coating differently with cycling (Fig. 5e).

Generally, cracks mostly originate from the surface of the coating, but their propagation is different according to the experiment results. To reveal the crack evolution, it is necessary to measure the crack density in the coating with increasing the number of cycles. In this study, the crack density is defined as the crack number per unit length at the $10 \mathrm{~mm}$ longitudinal section. Therefore, fatigue tests of some specimens were interrupted after cycling at a total mechanical strain of $0.35 \%$ for 50 cycles and 200 cycles, respectively. Along with the failed specimens, the crack density in the coating of the interrupted specimens in the longitudinal section was measured. The $10 \mathrm{~mm}$ investigated section is below fracture surface at the fracture specimens, while it is in the middle of the interrupted specimens gauge, and the orientation of statistic cracks is perpendicular to loading direction. The plots for the crack density in the coating versus number of cycles are shown in Fig. 6. It can be seen that during the first $0-50$ cycles the number of cracks increases very fast in the APS coating. After about 5 cycles there are five cracks in the whole longitudinal section of the coating, and two of them have arrived at the interface and the other cracks have passed through half of the coating. Eleven cracks have been found in the coating after 50 cycles and all have grown up to the interface. After 50 cycles, the growth rate of the crack density decreases in the APS coating. At about 200 cycles the crack density in the coating is similar to that in the failure specimen and it reaches saturation. But only three



Fig. 6 Crack density in coating as a function of number of cycles for coated M963 under OP TMF, at $\Delta \varepsilon_{\text {mech }} / 2=0.35 \%$ cracks were observed in the HVOF coating after 50 cycles. The growth rate of the crack density in the HVOF coating is distinctly lower than that in the APS coating at the beginning of the test and the crack density increases linearly.

The fracture of the specimen is ultimately determined by the failure of the substrate. Therefore, it is important to count the crack density in the substrate which has similar definition as the crack density in the coating. Along with the failed specimens, the crack density in the substrate at the longitudinal section of the former fatigue specimens interrupted was counted. The curve for the crack density in the substrate versus number of cycles is shown in Fig. 7. It can be seen that the crack density in the substrate of the APS coated specimens is the highest and the crack density in the bare specimen is the lowest among three specimen conditions. It seems from Fig. 7 and Table 1 that the higher the crack density is, the shorter the fatigue life will be.

When the coating cracked, channels exist for air to reach the substrate, resulting in substrate oxidation and subsequent crack initiation and growth. Compared to the degradation of the whole surface of the bare specimen, the environment attack in the substrate of coated specimens is only located at the tip of the crack of the coating. Therefore, the damage is more specific and severe, and crack initiation is easier in the substrate of the coated substrate. With an increase in number of cycles, this will cause the crack density in the substrate of the coated specimen higher than that of the bare substrate. Therefore, the life of the coated specimen was shorter than that of bare specimens. Thus, the coating loses its function when the coating cracks, and the substrate is destroyed which is demonstrated that many cracks appear in the substrate of coated



Fig. 7 Crack density in substrate as a function of number of cycles for coated and bare M963 under OP TMF, at $\Delta \varepsilon_{\text {mech }} / 2=0.35 \%$ 
Fig. 8 Microstructure of the longitudinal section of coated specimen for 200 cycles. a APS. b HVOF

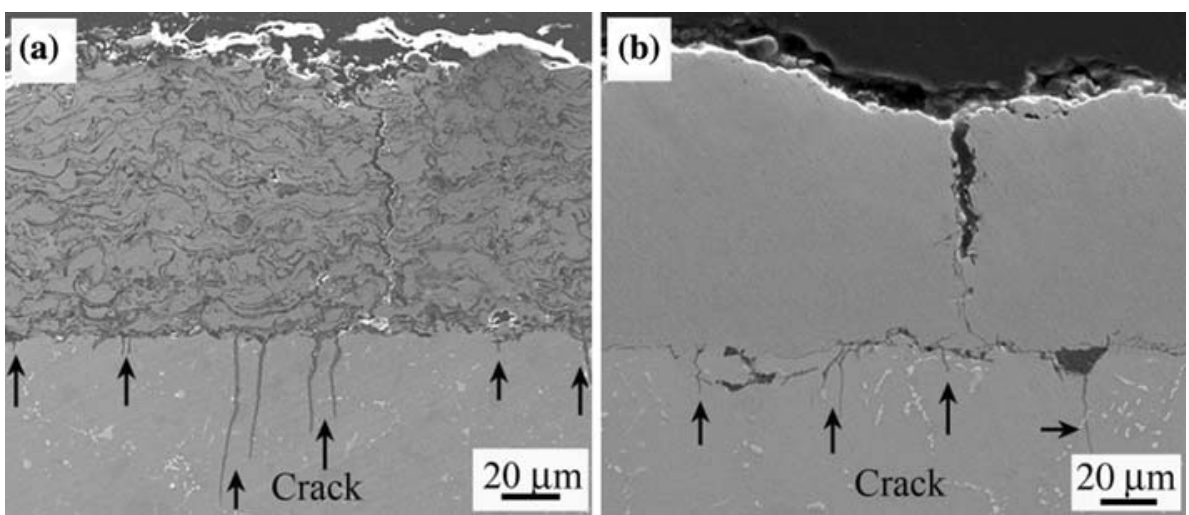

specimens after 200 cycles as shown in Fig. 8. It can be seen that cracks are much longer in the substrate of the APS coated specimen than that of the HVOF coated specimen; i.e., the damage of APS coated specimen is more serious. Compared Fig. 6 to 7, it can be seen that the crack density in the substrate is higher than that in the coating in coated specimens. When the coating cracks, most of the imposed forces are transferred to the substrate. When the cracks arrive at the interface between the coating and substrate, it is thought that there is little load in the coating, and most of the applied forces are imposed on the substrate [21]. Therefore, the high stress acts on the substrate, and this causes more cracks to originate in the substrate.

Fatigue cracking is influenced by surface condition, mean stress, frequency, and temperature [22], hold time at the maximum strain [23] etc. The crack initiation and propagation is general divided to three steps in this experiment: crack initiation in surface of the coating; propagation through the coating; initiation and propagation in the substrate. In step 1, the surface condition of two kinds of coatings dominates crack initiation. It can be seen that crack density in the APS coating is higher than that in the HVOF coating at first 50 cycles from Fig. 6; therefore, it is thought that the uneven surface of the APS coating provides sites for crack initiation; while it is difficult to crack at the flat surface of the HVOF coating, and this takes a long time to initiate a crack in the HVOF coating. In step 2 , splats and high density pores of the APS coating supply passages for the crack propagation; the solid coating prevents cracks propagate quickly in the HVOF coating, only when crack reaches a critical size its propagation rate increases. In step 3, more cracks originate in the substrate of the APS coated specimen as shown in Fig. 7. It is thought that more cracks in the APS coating pass through the coating than that in HVOF coating and this will bring more substrate to expose to the environment; therefore the damage of the substrate of APS coated specimen is more serious and the crack density is higher. The crack propagation in HVOF coated specimen was similar to the TMF behavior of LPPS NiCoCrAlY coated CMSX-4 [8]. The difficulty for crack initiation and the low propagation rate of crack in the coating are reasons for the longer fatigue life of HVOF coating than that of APS coating.

\section{Conclusions}

Thermomechanical fatigue behavior of NiCrAlY overlay coated nickel-based superalloy has been investigated in the present work. The cracking process in HVOF coating is different from those in APS one. It is found that the HVOF coating is potential for protective coatings under TMF conditions. The TMF damage mechanisms in two kinds of coatings were proposed and demonstrated by schematic diagrams to understand the crack evolution behavior in the coated specimens.

Acknowledgements This work was financially supported by the Center for Interfacial Materials, Shenyang National Laboratory for Materials Science, Institute of Metal Research, Chinese Academy of Sciences.

Open Access This article is distributed under the terms of the Creative Commons Attribution Noncommercial License which permits any noncommercial use, distribution, and reproduction in any medium, provided the original author(s) and source are credited.

\section{References}

1. Beele W, Marijnissen G, Van Lieshout A (1999) Surf Coat Technol 120-121:61

2. Schulz U, Leyens C, Fritscher K, Peters M, Saruhan-Brings B, Lavigne O, Dorvaux JM, Poulain M, Mévrel R, Caliez M (2003) Aerosp Sci Technol 7:73

3. Gleeson B, Mu N, Hayashi S (2009) J Mater Sci 44:1704. doi: 10.1007/s10853-009-3251-z

4. Théry PY, Poulain M, Dupeux M, Braccini M (2009) J Mater Sci 44:1726. doi:10.1007/s10853-008-3108-x

5. Kowalewski R, Mughrabi H (1998) Mater Sci Eng A 247:295

6. Totemeier TC, Gale WF, King JE (1996) Metall Mater Trans A 27:363 
7. Huang ZW, Wang ZG, Zhu SJ, Yuan FH, Wang FG (2006) Mater Sci Eng A 432:308

8. Jung A, Schnell A (2008) Int J Fatigue 30:286

9. Kadioglu Y, Sehitoglu H (1995) J Eng Mater T ASME 117:94

10. Kowalewski R, Mughrabi H (2000) In: Sehitoglu H, Maier HJ (eds) Thermo-mechanical fatigue behavior of materials: third volume, ASTM STP 1371. American Society for Testing and Materials, West Conshohocken, PA, p 3

11. Nützel R, Affeldt E, Göken M (2008) Int J Fatigue 30:313

12. Zhang YH, Knowles DM, Withers PJ (1997) Scripta Mater 37:815

13. Zamrik SY, Renauld ML (2000) In: Sehitoglu H, Maier HJ (eds) Thermo-mechanical fatigue behavior of materials: third volume, ASTM STP 1371. American Society for Testing and Materials, West Conshohocken, PA, p 119

14. Kwon JY, Lee JH, Jung YG, Paik U (2006) Surf Coat Technol 201:3483

15. Brandl W, Toma D, Krüger J, Grabke HJ, Matthäus G (1997) Surf Coat Technol 94-95:21
16. Ajdelsztajn L, Picas JA, Kim GE, Bastian FL, Schoenung J, Provenzano V (2002) Mater Sci Eng A 338:33

17. Jang HJ, Park DH, Jung YG, Jang JC, Choi SC, Paik U (2006) Surf Coat Technol 200:4355

18. Yuan FH, Chen ZX, Huang ZW, Wang ZG, Zhu SJ (2008) Corros Sci 50:1608

19. Hattali ML, Valette S, Ropital F, Mesrati N, Tréheux D (2009) J Mater Sci 44:3198. doi:10.1007/s10853-009-3426-7

20. Okazaki M, Okamoto M, Harada Y (2001) Fatigue Fract Eng M 24:855

21. Kadioglu Y, Sehitoglu H (1993) In: Sehitoglu H (ed) Thermomechanical fatigue behavior of materials: ASTM STP 1186. American Society for Testing and Materials, Philadelphia, p 17

22. Obrtlík K, Petrenec M, Man J, Polák J, Hrbáček K (2009) J Mater Sci 44:3305. doi:10.1007/s10853-009-3446-3

23. Lee SY, Lu YL, Liaw PK, Chen LJ, Thompson SA, Blust JW, Browning PF, Bhattacharya AK, Aurrecoechea JM, Klarstrom DL (2009) J Mater Sci 44:2945. doi:10.1007/s10853-009-3391-1 